\section{Decontamination technology assessments - who assesses the assessments?}

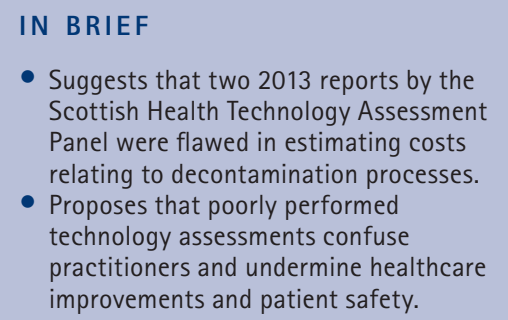

\author{
A. J. Smith
}

- Suggests that two 2013 reports by the Scottish Health Technology Assessment Panel were flawed in estimating costs

Proposes that poorly performed technology assessments confuse improvements and patient safety.

The driver to improve surgical instrument decontamination has been the introduction of VCJD into the UK population over the last two decades, although concerns over transmission of other infectious agents remain valid. Though significant improvements have been made in primary care, this is usually in spite of limited access to technical advice on decontamination equipment. A technology assessment for key elements of equipment and processes used in this environment should be welcomed. However, two reports by the Scottish Health Technology Assessment Panel are flawed in estimating costs associated with wrapping instruments, omission of appropriate references and inaccurate data in the costing models. These assessments contribute little to health economics debates, confuse practitioners and frustrate technical experts.

The $B D J$ has a long standing interest in publishing opinion and scientific manuscripts on the topics of infection prevention and instrument decontamination. Central to this has been calls for improvements in the evidence base for changes to policies and procedures and quite rightly so. A technological area where there has been significant change over the last decade has been medical device decontamination. In its broadest sense the decontamination of medical devices refers to the reprocessing of surgical instruments used in the wide variety of surgical specialties so that the tools of the surgeon's choice are available for subsequent patients. The end result of this process whether in hospitals or dental practice is sterile instruments at point of use.

Within hospitals most of this activity takes place behind closed doors in the sterile service department, out of sight of the surgical team until delays in turnaround

\footnotetext{
'Lead Microbiologist for Medical Device Decontamination NHS Glasgow \& Clyde, Professor of Clinical Bacteriology, Institute of Infection, Immunity and Inflammation, College of Medical, Veterinary \& Life Sciences, Glasgow Dental Hospital \& School, University of Glasgow, 378 Sauchiehall Street, Glasgow, GG2 3JZ

Correspondence to: Professor Andrew Smith

Email:andrew.smith@glasgow.ac.uk
}

\section{Refereed Paper}

Accepted 4 April 2013

DOI: 10.1038/sj.bdj.2013.681

British Dental Journal 2013; 215: 65-67 time force the cancellation of surgical lists. Much work has been undertaken in the UK to improve the quality of medical device reprocessing while keeping pace with increasing demands for extra volumes of work. Drivers to recent improvements were the identification of poor performance (including quantities of residual protein on instruments ready for re-use ${ }^{1-4}$ ) and the risk assessments undertaken to determine potential for transmission of iatrogenic CJD via surgical routes. ${ }^{5,6}$ The scientific principles underpinning the cleaning and sterilisation of surgical instruments has been understood for several decades. Unfortunately, many of these reports ${ }^{7-9}$ are now frequently overlooked by those new to the field. The emergence of vCJD in the human population has heightened concerns over iatrogenic transmission due to the relative resistance of the infective agent to steam sterilisation. Risk assessments have emphasised the importance of both cleaning and sterilisation as part of the instrument decontamination cycle. ${ }^{5}$

The policies, procedures and processes undertaken in sterile service departments are performed by relatively low paid technicians, managed by sterile service managers and supported by a team of engineers, infection control personnel and microbiologists. Departments are examined via external audit in order to achieve accreditation to meet the essential requirements of the Medical Devices Directive. ${ }^{10}$ These departments are now well managed manufacturers of sterile products.

However, in terms of the volume of work undertaken in reprocessing surgical instruments the largest number takes place outside of sterile service departments in general medical practitioners', general dental practitioners' and podiatrists' practices. ${ }^{11}$ Many of the procedures undertaken in these premises range from non-invasive to surgical such as, dental implant placement or toe nail resections. The workhorse of the process in sterilising instruments in primary care is the bench top steam steriliser. Two recent technology assessments by the Scottish health technology group have attempted to assess the practice of wrapping surgical instruments and the use of benchtop steam sterilisers in primary care. ${ }^{12,13}$

The principle of a health technology assessment is to be enthusiastically supported. In these difficult economic times, the increasing focus on value for money is to be welcomed. There are a number of flaws associated with these reports ${ }^{12,13}$ that require addressing before valid conclusions can be drawn. Technology assessments for health should be a multidisciplinary process to compile, analyse and summarise information about the scientific, technical and economic issues related to a health technology. European countries have 
agencies for health technology assessment and are members of the International Network of Agencies for Health Technology Assessment (INAHTA). The INAHTA has a checklist to improve the standard of HTAs which puts emphasis on several key aspects, such as explicit sources of information, literature search strategies, methods of critical appraisal and methods of economic analysis. ${ }^{10}$ The work produced by the Scottish health technology group falls short of these basic criteria on a number of fronts. The first technology assessment $002 / 10^{12}$ provides advice on the question: "what is the evidence for a change in current practice of keeping dental instruments clean but unwrapped after sterilisation and before use?' Firstly, this question is based on an incorrect assumption; the evidence from our survey work ${ }^{15,16}$ demonstrated that current practice by the majority of dental practices in Scotland is to wrap instruments after sterilisation (some 70\% using type N sterilisers and 50\% using type B sterilisers wrapped dental instruments after sterilising and before use). Since the majority of dental practitioners are already wrapping their instruments it seems difficult to determine how the figure of an additional £24 million was calculated.

In the technology assessment ${ }^{12}$ no details were provided on the sources of information, literature search strategy or methods of critical analysis. Much work on surgical instrument sterilisation including wrapping was undertaken in the 1950s and 1960s. ${ }^{7-9}$ The group also fail to place their technology assessment into the context of European legislation related to Medical Devices, for example, Medical Devices Directive 93/42/EEC Annex 18.3 (Packaging) and European standards (EN 868 series) for packaging and International standards (ISO 11607 - packaging for terminally sterilised products for healthcare). The lack of transparency in how risks and cost effectiveness were assessed in the absence of robust surveillance systems in primary dental care to detect adverse events associated with deficiencies in wrapping dental surgical instruments makes interpretation difficult if not impossible. At present adverse events, such as transmission of infection following dental treatment are dependent on an ad hoc reporting system and as such only a limited number of incidents are actually reported. ${ }^{17,18}$ There is evidence to demonstrate the widespread generation of aerosols in dental practice ${ }^{19}$ and the potential for transmission of microbes via dental equipment. ${ }^{20}$ It is unclear whether any of this evidence was taken into account during the decision making process.

The second technology assessment ${ }^{13}$ attempts to answer the question: "would the provision of vacuum sterilisers to dental practices in Scotland provide sufficient benefit in terms of increased patient safety to justify the financial outlay and on-going revenue costs?' No details are provided in the statement on the search strategy used or criteria used for assessing quality, indeed a preliminary review of published work has identified key missing publications. For example work by Andersen et al. ${ }^{21} \mathrm{dem}-$ onstrated that none of the tested small, non-vacuum autoclaves could consistently kill bacterial spores while the vacuum autoclaves could. The advice statement further confuses users since it appears to acknowledge that the apparatus under assessment does fail to sterilise equipment '...outcome measures relate to biological measures of contamination' but appear to be basing the technology assessment on the absence of adverse patient events. Further gaps in the technology assessment are highlighted by the statement '...it was not possible to obtain the full text of other studies...' - which studies were these? And why where they ignored? In terms of cost effectiveness no details were provided on the equipment or its specification making meaningful interpretation of clinical use impossible. This together with technical inaccuracies - for example why undertake both Bowie Dick and Helix tests? Further costing appraisals fail to take into account changes in the periodic testing of some types of benchtop steam steriliser which do not need quarterly testing but validation every second year or 2,000 cycles. These data should have been included in costing models.

In conclusion, the two technology assessments by the Scottish technology group presented no risk assessment or cost effectiveness analysis such as decision analytical modelling; on the technology under assessment therefore any conclusions on risk and cost-effectiveness are meaningless. Technology risk assessments have a valuable role to play in healthcare economics; however, these must be robust, technically accurate and transparent. Poorly performed technology assessments further confuse practitioners looking to make informed choices in difficult economic times but perhaps more importantly undermine healthcare improvements and patient safety.

The contents of this article arose following several discussions with Professor David Hurrell, Professor of Medical Device Decontamination, University of Highlands and Islands. This was to have been a jointly co-authored paper with David; unfortunately he passed away after a long illness in November 2012.

1. Baxter R L, Baxter H C, Campbell G A et al. Quantitative analysis of residual protein contamination on reprocessed surgical instruments. J Hosp Infect 2006; 63: 439-444.

2. Smith A J, Letters $S$, Lange A, Perrett D, McHugh S, Bagg J. Residual protein levels on reprocessed dental instruments. J Hosp Infect 2005; 61: 237-241.

3. Murdoch H, Taylor D, Dickinson J, Walker J T, Perrett $D$, Raven N D et al. Surface decontamination of surgical instruments: an ongoing dilemma. J Hosp Infect 2006; 61: 237-241.

4. Vassey $M$, Budge $C$, Jones $P$ et al. A quantitative assessment of residual protein levels on dental instruments reprocessed by manual, ultrasonic and automated cleaning methods. Br Dent J 2011; 210: E14.

5. Economics and Operational Research Division. Potential vCJD transmission risks via dentistry: an interim review. London: $\mathrm{DH}, 2007$.

6. Kirby E, Dickinson J, Vassey M et al. Bioassay studies support the potential for iatrogenic transmission of variant Creutzfeldt Jakob disease through dental procedures. PLoS One 2012; 7: e49850.

7. Darmady E M, Hughes K E A, Jones J D, Verdon PE. Failure of sterility in hospital ward practice. Lancet 1959; 273: 622-624.

8. Medical Research Council. A report to the Medical Research Council by the working party on pressure steam sterilizers. Sterilisation by steam under increased pressure. Lancet 1959; 273: 425-435.

9. Medical Research Council. Sterilisation by steam under increased pressure: a second communication by the working party on pressure steam sterilisers. Lancet 1960; 276: 1243-1244.

10. MHRA. Medical Devices Directive 2007/47/EC.

11. Scottish Executive Health Department. Healthcare associated infection: Review of decontamination services and provision across NHS Scotland (The 'Glennie' Framework). 2001. www.sehd. scot.nhs.uk/publications/GlennieFramework.pdf (accessed May 2013)

12. Wrapping dental instruments. Advice statement 002/10. Scottish Health Technology Group. www.healthcareimprovementscotland.org/programmes/medicines_and_technologies/shtg_-advice_statements/advice_statement_002-10. aspx?theme $=$ default (accessed May 2013).

13. Benchtop steam sterilisers in primary care. Advice statement 003/11. Scottish Health Technology Group. www.healthcareimprovementscotland. org/programmes/clinical_cost_effectiveness/ shtg/advice_statements/advices/advice_statement_003-11.aspx (accessed May 2013).

14. International Network of Agencies for Health Technology Assessment. HTA checklist. www.inahta. org/HTA/Checklist/ (accessed May 2013).

15. Scottish Executive Health Department. NHS Scotland: Sterile Services Provision Review Group: survey of decontamination in general dental practice, 2004 www.scotland.gov.uk/ Publications/2004/11/20093/45218 (accessed May 2013).

16. Smith A J, Bagg J, Hurrell D, McHugh S. Sterilisation of re-usable instruments in general dental practice. Br Dent J 2007: 202: E22. 
17. Martin M V, Hardy P. Two cases of oral infection by methicillin resistant Staphylococcus aureus. Br Dent J 1991: 170: 63-64.

18. Rokadiya S, Malden N J. An implant periapical lesion leading to acute osteomyelitis with isolation of Staphylococcus aureus. Br Dent J 2008; 205:
489-491.

19. Bennett A M, Fulford M R, Walker T J, Bradshaw D J, Martin M V, Marsh P D. Microbial aerosols in general dental practice. Br Dent J 2000; 189: 664-667.

20. Kurita H, Kurashina K, Honda T. Nosocomial transmission of methicillin resistant Staphylococcus aureus via the surfaces of the dental operatory. $\mathrm{Br}$ Dent J 2006; 201: 297-300.

21. Andersen HK, Fiehn NE, Larsen T. Effect of steam sterilization inside turbine chambers of dental turbines. Oral Surg Oral Med Oral Pathol Oral Radiol Endod 1999: 87: 184-188. 